\title{
Perioperative implication of the endothelial glycocalyx
}

\author{
Jong Wook Song ${ }^{1, *}$ and Michael S. Goligorsky ${ }^{2, *}$ \\ ${ }^{1}$ Department of Anesthesiology and Pain Medicine, Yonsei University College of Medicine, Seoul, Korea, ${ }^{2}$ Renal \\ Research Institute and Departments of Medicine, Pharmacology, and Physiology, New York Medical College, \\ Valhalla, NY, USA
}

The endothelial glycocalyx (EG) is a gel-like layer lining the luminal surface of healthy vascular endothelium. Recently, the EG has gained extensive interest as a crucial regulator of endothelial funtction, including vascular permeability, mechanotransduction, and the interaction between endothelial and circulating blood cells. The EG is degraded by various enzymes and reactive oxygen species upon pro-inflammatory stimulus. Ischemia-reperfusion injury, oxidative stress, hypervolemia, and systemic inflammatory response are responsible for perioperative EG degradation. Perioperative damage of the EG has also been demonstrated, especially in cardiac surgery. However, the protection of the EG and its association with perioperative morbidity needs to be elucidated in future studies. In this review, the present knowledge about EG and its perioperative implication is discussed from an anesthesiologist's perspective.

Keywords: Endothelial glycocalyx; Mechanotransduction; Permeability; Sulodexide.

\section{Introduction}

The luminal surface of the healthy vascular endothelium is covered with glycocalyx, a gel-like layer enriched with carbohydrates. Its dimensions vary according to the type of vasculature, ranging from $0.2 \mu \mathrm{m}$ to more than $2 \mu \mathrm{m}$. The endothelial gly-

${ }^{\star}$ Co-corresponding author: Jong Wook Song, M.D.

Department of Anesthesiology and Pain Medicine, Yonsei University College of Medicine, 50, Yonsei-ro, Seodaemun-gu, Seoul 03722, Korea

Tel: 82-2-2228-8516, Fax: 82-2-364-2951

Email: sjw72331@yuhs.ac

ORCID: https://orcid.org/0000-0001-7518-2070

${ }^{\star}$ Co-corresponding author: Michael S. Goligorsky, M.D., Ph.D.

Renal Research Institute, Basic Sciences Bldg, New York Medical College, 15 Dana Road, Valhalla, NY 10595, USA

Tel: 1-914-594-4730

Email: Michael_goligorsky@nymc.edu

Received: March 4, 2018.

Revised: March 8, 2018 (1st); March 25, 2018 (2nd).

Accepted: March 25, 2018.

Korean J Anesthesiol 2018 April 71(2): 92-102

https://doi.org/10.4097/kjae.2018.71.2.92 cocalyx (EG) consists of various types of glycosaminoglycans covalently attached to plasma membrane-bound core proteoglycans. Heparan sulfate comprises $50-90 \%$ of endothelial glycosaminoglycans, and the remainder is a mixture of hyaluronic acid, dermatan, keratan, and chondroitin sulfates [1]. The high degree of sulfation of heparans, dermatans, keratans, and chondroitin sulfates, as well as the carboxyl groups of hyaluronic acid, contribute to the net negative charge of the EG, which influences the interaction between the EG and blood constituents. Two families of proteoglycans, syndecans 1-4 (single membrane-spanning domain) and glypicans 1-6 (glycosylphosphatidylinositol-anchored), provide the membrane-tethered scaffold for these glycosaminoglycans except hyaluronic acid, which is attached to the osteopontin receptor CD44. In addition, the EG incorporates diverse biologically active molecules, including extracellular superoxide dismutase, xanthine oxidoreductase, lipoprotein lipase, various cytokines, and regulators of coagulation. Several glycoprotein families (selectins, integrins, and immunoglobulins) are also incorporated in the EG. Pro-inflammatory stimuli increase the expression of these glycoproteins to act as adhesion molecules.

In a healthy vasculature, the EG and intercalated blood constituents form the endothelial surface layer (ESL). As a barrier

(c) This is an open-access article distributed under the terms of the Creative Commons Attribution Non-Commercial License (http://creativecommons.org/ licenses/by-nc/4.0/), which permits unrestricted non-commercial use, distribution, and reproduction in any medium, provided the original work is properly cited. 
between the endothelium and circulating blood, this layer regulates vascular permeability [2], as well as the interaction between endothelial and circulating blood cells $[3,4]$. The EG senses the shear stress of blood flow and transduces it into intracellular signals [5]. In addition, the binding and activation of various ligands and cell surface receptors may be affected by the EG $[1,6]$. The EG is not a static structure and is maintained in an equilibrium of continuous shear-induced shedding and synthesis. This constant state is, however, quite vulnerable and tends to disintegrate in response to various stressors, including ischemia-reperfusion, oxidative stress, hypervolemia, endotoxins, and other pro-inflammatory stimuli. The degradation of the EG leads to increased vascular permeability, facilitated transmigration of inflammatory cells, impaired mechanotransduction, reduced antioxidant activity, compromised anti-coagulant properties on the endothelial surface, and further activation and propagation of danger signals.

\section{Physiologic Functions of the EG}

\section{Vascular permeability}

In the classic Starling's principle, the net fluid flux across the inter-endothelial junction is determined by the balance between hydrostatic and oncotic pressure gradients [7]. High hydrostatic pressure in the vascular lumen drives fluid to the interstitial space, whereas lower levels of proteins in the interstitial space compared to the plasma results in opposing forces for hydrostatic filtration. This can be expressed by the following equation:

$$
\mathrm{J}_{\mathrm{v}} / \mathrm{A}=\mathrm{L}_{\mathrm{p}}\left(\mathrm{P}_{\mathrm{c}}-\mathrm{P}_{\mathrm{i}}\right)-\sigma\left(\pi_{\mathrm{c}}-\pi_{\mathrm{i}}\right)
$$

where $\mathrm{J}_{\mathrm{v}} / \mathrm{A}$ is the filtration rate per area, $\mathrm{L}_{\mathrm{p}}$ is the hydraulic conductance, $\mathrm{P}_{c}$ is the intravascular hydrostatic pressure, $\mathrm{P}_{\mathrm{i}}$ is the interstitial hydrostatic pressure, $\sigma$ is the reflection coefficient, $\pi_{c}$ is the plasma oncotic pressure, and $\pi_{\mathrm{i}}$ is the interstitial oncotic pressure.

However, several quantitative studies revealed that actual fluid filtration differed from the amount predicted by the classic Starling's principle. As hydrostatic pressure gradually decreases from the arteriolar to venular ends of the capillary, it was assumed that fluid is filtered to the interstitium along the arteriolar side of the capillaries and then reabsorbed at the venular side. This model has been refuted in later studies [8,9]. Revisions to Starling's principle has been made, suggesting that the return of fluids to the circulation occurs exclusively via lymphatic drainage. In contrast to earlier experiments, which were conducted in models where the interstitial oncotic pressure was near zero [10], Levick [11] used accurate measures of interstitial oncotic pressure, which is almost half the plasma, and showed that the net filtration pressure predicted by the classic Starling's equation was in far excess of the observed lymphatic flow. Moreover, when the interstitial oncotic pressure was raised, the increase in net fluid filtration was much smaller than expected [8]. These discrepancies indicated that interstitial protein concentration plays a minor role in the generation of the oncotic pressure gradient across the capillary wall. The introduction of the glycocalyx-cleft model helped to resolve the paradox, and Starling's principle was revised to the following:

$$
\mathrm{J}_{\mathrm{v}} / \mathrm{A}=\mathrm{L}_{\mathrm{p}}\left(\mathrm{P}_{\mathrm{c}}-\mathrm{P}_{\mathrm{i}}\right)-\sigma\left(\pi_{\mathrm{c}}-\pi_{\mathrm{sg}}\right)
$$

where $\pi_{\mathrm{sg}}$ is the subglycocalyx oncotic pressure.

The EG acts as a molecular sieve of plasma proteins $[9,12]$, and filtered fluid accelerates through the narrow junctional breaks. If this downstream fluid velocity approaches the upstream diffusion velocity of interstitial proteins, a washout of the diffusing proteins can maintain the protein concentrations in the sub-glycocalyx area at a very low level. Consequently, the effective oncotic pressure gradient opposing hydrostatic filtration is greater than the difference in oncotic pressure between the plasma and interstitium, reducing the basal fluid filtration rate to approximately the normal lymphatic drainage rate [13]. Enzymatic removal of EG components results in increased hydraulic conductivity, protein flux, albumin excretion, and edema [14-16]. When the negative charge of the EG was removed, increased permeability to albumin or dextrans were observed $[17,18]$. This evidence indicates that EG is a major determinant of vascular permeability.

In addition to a passive barrier role, recent studies suggested that the EG may regulate vascular permeability by acting as a mechanotransducer of flow-mediated shear stress [19]. According to Starling's principal, hydrostatic pressure and fluid flux should have a linear relationship if $\mathrm{L}_{\mathrm{p}}$ is held constant. However, it has been shown that increases in hydrostatic pressure results in an increase in $\mathrm{L}_{\mathrm{p}}$, thus resulting in a non-linear elevation of net fluid flux [20-23]. The shear-induced increase in $\mathrm{L}_{\mathrm{p}}$ involves the activation of endothelial nitric oxide synthase (eNOS) and resultant alterations of junctional proteins [24]. The heparanase treatment of bovine endothelial cells abolished the shear-induced increase in $\mathrm{L}_{\mathrm{p}}[23,25]$, suggesting a non-Starling mechanistic role of EG in the regulation of vascular permeability.

\section{Mechanotransduction}

One of the main roles of EG is represented by the mechanotransduction of blood flow-mediated shear stress to the cytoskeleton, nucleus, and enzymatic reactions, which is essential for vascular homeostasis. The EG functions as a sensor of mechanical forces exerted on the endothelial surface [26], in concert 
with other sensors including G-protein-coupled receptors [27], stretch-sensitive ion channels [28], rheological properties of the plasma membrane [29,30], caveolar structures [31], and integrins and focal adhesion molecules [32]. These mechanosensors initiate intracellular signaling such as increases in cytosolic calcium, the activation of eNOS [33], Rho-family guanosine triphosphatases, tyrosine kinases, Ras, Erk, and JNK; the phosphorylation of platelet endothelial cell adhesion molecule-1 (PECAM-1) intracellular domain [34]; and cytoskeletal remodeling [35], especially at the sites of highest tension like cell-cell junctions [36]. Physiologically, shear stress on the endothelium activates eNOS via the phosphorylation of S617, S635, S1177/ S1179 residues by calmodulin kinase, PI3K/Akt, and PKA pathways [37]. In addition, shear stress also induces sirtuin 1, a nicotinamide adenine dinucleotide (NAD)-dependent deacetylase, which enhances eNOS activity through deacetylation at Lys496 and Lys506 [38]. Physiological shear stress also induces transcription factors such as Kruppel-like factor-2 and nuclear factor-like-2, both of which are responsible for the induction of eNOS and antioxidant defense [39]. In contrast, in endothelial cells, perturbed blood flow induces the activation of the nuclear factor kappa B (NF- $\kappa$ B) pathway and activator protein-1, which participate in the acquisition of a pro-inflammatory phenotype by endothelial cells [40,41]. Defective mechanosensing and the resulting reduction in the shear-induced release of nitric oxide (NO) is associated with decreased eNOS activity. Direct pulling of the EG components and core proteins using atomic force microscopy results in a rapid $\mathrm{Ca}^{2+}$ influx and $\mathrm{NO}$ production $[33,42]$, whereas enzymatic removal of EG [43], inhibition or knockdown of specific transient receptor potential (TRP) channels [44,45], or disruption of caveolae [46], all of which result in the impairment of flow-induced NO production.

NO has a crucial role in vascular homeostasis including the regulation of vascular tone, permeability, and inflammatory phenotype [47]. Decreased bioavailability and uncoupling of eNOS are associated with increased oxidative and nitrosative stress as well as endothelial dysfunction [48]. Of note, endothelial dysfunction induced by the disintegration of the EG and defective mechanotransduction may accelerate the further loss of the EG, leading to a vicious cycle of endothelial dysfunction. Decreased bioavailability of NO can increase exocytosis of lysosome-related organelles, which are responsible for the intrinsic mechanism of the EG degradation, via reduced S-nitrosylation of the N-ethylmaleimide-sensitive factor [49]. Furthermore, sirtuin 1 deficiency also affects vascular homeostasis. Recently, we reported that endothelium-specific sirtuin 1 knock-out mice have a significantly reduced whole body EG volume compared with wild-type mice [50]. Sirtuin 1-mediated deacetylation of Forkhead box O (FoxO1) DNA-binding protein is required for its active conformational change and enhanced cellular protec- tion from oxidative stress [51,52]. Deficient sirtuin 1 expression or activity, which is associated with diverse vasculopathies [53], leads to susceptibility to oxidative stress. Oxidative stress activates disintegrin and metalloproteinase domain-containing protein 17 (ADAM-17) [54]. Activation of this enzyme contributes to cleavage of syndecan, which results in the shedding of EG [55]. Additionally, sirtuin 1 deficiency activates NF- $\mathrm{B}$, which induces transcriptional activation of heparanase, one of the target genes of this transcription factor [56,57]. Subsequently, increased heparanase activity leads to the enzymatic removal of heparan sulfate side chains from the EG and disintegration of ESL.

\section{Role in blood cell-endothelial interactions}

The EG shields the endothelium from interactions with circulating blood cells. The length of projections of cell adhesion molecules, including selectins (PECAM, vascular cell adhesion molecules (VCAMs), and ICAMs (intercellular adhesion molecules)) and integrins (CD11/CD18), are shorter than the thickness of the EG [58]. Thus, intact EG inhibits firm adhesion of leukocytes and platelets, whereas shedding of the EG facilitates their adhesion. In rodent cremaster muscle preparation, degradation of the EG by oxidized lipoproteins or tumor necrosis factor alpha (TNF- $\alpha$ ) increased platelet or leukocyte-endothelial adhesion [3,59]. Similarly, chemotactic peptide fMLP (formylMet-Leu-Phe) degraded the EG and increased adhesion of leukocytes, while the matrix metalloprotease (MMP) inhibitor doxycycline attenuated the degradation of the EG and reversed the facilitated adhesion of leukocytes $[4,60]$. Knockout of syndecan-1 in mice resulted in increased adhesion and transmigration of leukocytes under pro-inflammatory stimuli as well as basal conditions [61].

\section{Mechanisms of Glycocalyx Degradation}

A variety of enzymes and reactive oxygen species (ROS) contribute to the degradation of the EG under inflammatory conditions. Activated neutrophils produce ROS and reactive nitrogen species (RNS), and release granules that contain proteases responsible for EG degradation [62]. Heparanase liberated from mast cells cleaves heparan sulfate side chains from membrane-bound core proteoglycans [63-65]. Additionally, hyaluronic acid can be cleaved by hyaluronidase. Although these enzymes are capable of fragmentation and removal of major glycosaminoglycans from the EG, more extensive shedding can occur by damage to core proteoglycans that constitute the backbone of ESL. Proteases released and activated under inflammatory conditions have been demonstrated to cause shedding of the EG [66]. MMPs are thought to cleave the syndecan ectodomain $[60,66,67]$. Other potential sheddases include 
neutrophil elastase, thrombin, plasmin, tryptase, and cathepsin B [68]. Upon appropriate inflammatory stimuli, phagocytes release their vesicles containing MMPs [67]. Doxycycline, a non-selective inhibitor of MMP activity, decreases shedding of the glycocalyx $[60,66,67]$. High affinity of MMP to heparan sulfate promotes the immobilization of MMPs within the ESL [69] and potentially enhances its destructive potential. Furthermore, MMPs have also been suggested to cleave CD44 [70-72].

ROS/RNS can damage the EG directly. One of the major sources of ROS is neutrophil-derived myeloperoxidase bound to the negatively charged glycosaminoglycan side chains [62]. The cleavage of HS after increased oxidative stress shows a similar pattern of increase in macromolecular passage compared to treatment with heparanase $[73,74]$. In addition, core proteoglycans are also susceptible to oxidative/nitrosative stress [62]. Furthermore, ROS/RNS can facilitate shedding of the EG via activation of MMPs and inhibition of endogenous protease inhibitors $[54,62]$.

EG-degrading mediators are mainly released by inflammatory cells such as neutrophils and mast cells as described above. However, endothelial cells can be directly stimulated by inflammatory mediators such as TNF- $\alpha$ or lipopolysaccharides (LPS) to secrete molecules that contribute to the disintegration of the EG [59,75-78]. Recently, we showed using stochastic optical reconstruction microscopy (STORM) that the degradation of the EG is also mediated by the exocytosis of Weibel-Palade bodies (WPBs) and secretory lysosomes, which are visualized as patch loss or craters of the EG in a very early course of a rodent sepsis model [79]. Exocytosis of WPB and secretory lysosomes are one of the earliest responses of activated endothelial cells [80]. WPBs are rod-shaped organelles $(0.2 \mu \mathrm{m} \times 2-3 \mu \mathrm{m})$ characteristic of endothelial cells and containing various kinds of proteins, enzymes, and inflammatory mediators. Known inducers of exocytosis of WPB include thrombin, histamine, leukotrienes, complements, superoxide anion, vascular endothelial growth factor (VEGF), sphingosine-1-phosphate, serotonin, vasopressin, and epinephrine [81-83]. The mechanisms of exocytosis of lysosomal-related organelles, such as WPB and secretory lysosomes, involves docking to the plasma membrane via soluble N-ethylmaleimide sensitive factor (NSF) attachment protein receptors (SNAREs) [81]. An interaction of NSF and its adaptor synaptosome-associated protein ( $\alpha$-SNAP) with SNARE proteins is required to prime WPB for exocytosis. This process can be inhibited by S-nitrosylation of NSF, implicating a crucial role of $\mathrm{NO}$ in the regulation of exocytosis of lysosomal-related organelles [49]. Notably, the prevention of exocytosis of lysosomal-related organelles with a NO donor improved survival of animals with severe experimental sepsis [79].

\section{Perioperative Degradation of Glycocalyx}

Acute degradation of the EG has been shown in patients with major surgery, especially those with cardiac surgery [84-88], as well as those with sepsis [89-92] and major trauma [93,94]. Elevated levels of EG degradation markers are associated with poor outcome in septic and critically ill patients [92,93,95-97]. In the perioperative setting, high postoperative syndecan-1 levels are correlated with greater incidence of severe acute kidney injury in pediatric patients that underwent cardiac surgery [98]. It has been proposed that ischemia-reperfusion (I/R) injury, oxidative stress, hypervolemia, and massive hemorrhage contribute to the perioperative degradation of the EG. I/R injury can disrupt the integrity of the EG through increased oxidative stress, secondary inflammatory response, and microvascular endothelial dysfunction $[99,100]$. The degradation of EG has been well demonstrated in animal models of mesenteric or cardiac ischemia [77]. I/ $\mathrm{R}$ injury is also commonly encountered during cardiac, major vascular, and transplantation surgeries. Indeed, an elevation in the serum concentration of EG components, which reflects the degradation of the EG and release of its components into the circulation has been shown in cardiac and aortic surgeries [84-86]. Furthermore, I/R injury alone is not solely responsible for cardiac surgery-induced EG degradation. Cardiopulmonary bypass $(\mathrm{CPB})$ induces an intense systemic inflammatory response, which is characterized by the activation of the coagulation system and complement pathway, I/R injury, recruitment of inflammatory cells in multiple organs, surge of pro-inflammatory cytokines, increased oxidative stress, activation of serine proteases, and microvascular endothelial dysfunction [101]. The inflammatory response following $\mathrm{CPB}$ is initiated by contact of blood with a non-endothelialized foreign surface and further accentuated by endotoxemia due to the translocation of LPS from the intestine to circulation [102-104]. Taken together, the inflammatory phenotype following CPB resembles that of sepsis, in which the degradation of the EG has been well-documented [105].

Interestingly, patients undergoing off-pump coronary artery bypass (OPCAB) showed a similar increase in the serum concentrations of the EG components, despite circumventing $\mathrm{CPB}$ [85]. This may have been due to the inevitable warm I/R injury from the temporary ligation of coronary arteries during grafting, hypotension, and the low cardiac output leading to the hypoperfusion of vital organs following cardiac displacement for the exposure of coronary arteries. Moreover, it was suggested that the release of atrial natriuretic peptide (ANP) during surgery may induce shedding of the EG. Cardiomyocytes in the atrium of the heart secrete ANP in response to a stretch in the atrium. In addition to its renal effect, ANP is known to increase microvascular permeability. Experimental studies demonstrated that 
ANP induced rapid shedding of EG via a cyclic guanosine monophosphate (cGMP)-linked proteolytic pathway, and resulted in increased net fluid flux and colloid extravasation to the interstitial space [106]. Furthermore, intracoronary infusion of ANP showed a dose-dependent effect on the EG shedding [107]. The displacement of the heart during OPCAB impairs ventricular filling and causes a stretch or compression of the atrium, leading to the release of ANP [108].

A reduction in the EG dimension was also shown in animal models of hemorrhagic shock $[109,110]$. However, the mechanism of shedding has not yet been elucidated. It is well known that patients with severe multiple trauma have diminished EG volume, probably due to massive hemorrhage and systemic inflammatory response [94]. Massive hemorrhage is not uncommon during major surgeries; however, no clinical study has addressed this issue so far.

\section{Strategies to Protect EG}

The natural regeneration of the EG appears to be slow. Animal studies suggest that the restoration of a hydrodynamically relevant volume of the EG following enzymatic degradation requires up to seven days [111]. There has been little evidence for the time-course of EG degradation and restoration during the perioperative period. In cardiac surgery, the concentrations of serum EG components peaked at the end of CPB, followed by a rapid decrease and return to near normal values at $24 \mathrm{~h}$ post-operation [84]. However, the serum concentrations of those fragments cannot be considered as a reliable indicator of EG regeneration, whereas an initial rise in serum can be a marker for degradation. Considering that the EG degrading stimuli can last several days postoperatively, the restoration of the EG may take a longer time. Therefore, strategies to minimize the degradation or accelerate restoration may have high clinical relevance.

\section{Avoiding hypervolemia}

Hypervolemia can result in the shedding of the EG, which is induced by the release of ANP due to atrial stretch. When colloid solutions are administered to normovolemic patients, $60 \%$ of the infused solution was extravasated immediately, whereas almost the entire volume was maintained within the intravascular space in an acute normovolemic hemodilution setting [112,113]. The prophylactic administration of fluids upon the induction of general or neuraxial anesthesia has long been advocated to counteract hypotension due to an anesthesia-induced decrease in cardiac preload. However, this practice cannot be recommended considering the role of the EG in fluid management. Furthermore, preloading of fluids did not show consistent efficacy for decreasing the incidence of hypotension or requirement for vasopressors after neuraxial anesthesia $[114,115]$. Moreover, liberal perioperative fluid administration leading to a positive fluid balance has been associated with increased morbidity [116]. Perioperative degradation of the EG may provide one rationale for restrictive fluid administration by a goal-directed protocol; however, the clinical impact of liberal versus restrictive fluids needs more extensive discussion [117] and is beyond the scope of this review.

\section{Albumin}

The EG can be stabilized by supplementation with albumin within the ESL [63]. The intercalation of albumin can provide protection against oxidative damage owing to an oxidizable sulfhydryl group of albumin, excessive attachment of leukocytes and platelets, and maintenance of shear-induced vasodilatation [63,118]. In addition, albumin carries sphingosine-1-phosphate, which inhibits MMP activity on the endothelium [119]. In an animal model for heart transplantations, the addition of histidine-tryptophan-ketoglutarate solution, which contains albumin

Intact glycocalyx
$\begin{aligned} & \text { Leukocyte } \\ & \text { deterrent }\end{aligned}$

Fig. 1. The physiological role of intact endothelial glycocalyx is represented. The degradation of glycocalyx leads to various pathologies. Possible tools for the restoration of glycocalyx are shown. MMP: matrix metalloprotease, ecSOD: extracellular superoxide dismutase, NO: nitric oxide. 
reduced EG degradation [120]. In an experimental model of massive hemorrhage, resuscitation with plasma showed partial restoration of the EG, whereas lactated Ringer resuscitation did not [110]. These data suggest a possible role of albumin in the protection of the EG, although there is a paucity of direct clinical evidence.

\section{Pharmacologic agents}

A variety of pharmacological agents has been used to restore or prevent the degradation of the EG (Fig. 1). Agents that potentially interfere with EG degradation include antioxidants [121], antithrombin III [122], MMP inhibitor doxycycline [67], TNF- $\alpha$ analogue etanercept [123], NO donors [124], hydrocortisone [125], and volatile anesthetics [126,127]. However, these promising experimental study results have not yet been translated into clinical practice. Other methods to prevent EG degradation involve the supplementation of EG constituents such as heparan sulfate or hyaluronic acid [128]. Although accelerated restoration of the EG was achieved in vitro, heparan sulfate and hyaluronic acid could not reconstitute EG in vivo in a sepsis model [129]. The lack of effect in vivo can be explained by the overwhelming degradation process, which cannot be suppressed by the supplementation of EG components. Interestingly, we have reported a remarkable effect with sulodexide, an $8: 2$ mixture of fast-moving heparin and dermatan sulfate, on the restoration of the EG and survival benefit in a mouse model of severe sepsis [129]. The superior efficacy of sulodexide is thought to be due to its dual action, supplementation of EG constituents, and concomitant inhibition of degrading enzymes. Fast-moving heparin components of sulodexide, as a close mimic of heparan sulfate, are responsible for heparanase inhibition at basic clusters of heparanase in a competitive manner [130]. The dermatan sulfate fraction interacts with the active zinc binding site of the pro-MMP-9 molecule to block its conformational change into an active form [131]. It has also been reported that sulodexide attenuates the release of MMP-9 from leukocytes [132]. Clinically, Broekhuizen et al. [133] demonstrated that oral sulodexide administration for two months partially restored the thickness of the EG in patients with type 2 diabetes using sidestream dark field imaging of sublingual microcirculation. It is uncertain whether sulodexide would show a comparable effect in the perioperative setting. The required dose of sulodexide was estimated to be much higher to reconstitute the EG in a severe sepsis model [129]. Although sulodexide is known to exert minimal in vivo anti-coagulant effects due to its preferential uptake by the endothelium [134], care should be taken for its application in the perioperative setting because of a potential bleeding tendency from the administration of large doses. From this point of view, chemically modified, non-anticoagulant variants of heparin could be fascinating candidates for the protection of EG [135-137].

\section{Emerging Therapy to Restore the Degraded Glycocalyx}

We have recently invented liposomal nanocarriers of the preassembled glycocalyx [138]. in vitro, ex vivo, and in vivo testing of these liposomes showed that they expeditiously restore glycocalyx in cultured endothelial cells stripped of EG by prior treatment with heparanase, restore mechanotransduction in isolated perfused arterioles, improve their flow-induced NO production, and partially restore renal microcirculation in LPS-injected mice. Collectively, these findings augur potential therapeutic benefits in restoring the EG in diverse conditions associated with the loss of EG.

\section{Conclusion}

The structure, function, and degradation of EG under various pathological conditions have been well recognized. I/R injuries, oxidative stress, hypervolemia, and systemic inflammatory responses promote EG degradation. Considering its unique location and diverse role in endothelial function, protecting the EG would probably improve clinical outcome after surgery. The degradation of EG during the perioperative period, especially in cardiac surgery, is a well-known phenomenon. Further study is needed to elucidate the clinical impact of EG degradation in the perioperative setting. Currently, no pharmacological tools for the restoration of EG are clinically available. However, attempts to minimize EG degradation, including avoidance of hypervolemia, and reducing the stress response and systemic inflammation, should be adopted by anesthesiologists. Furthermore, a novel strategy to restore degraded EG using liposomal nanocarriers of the preassembled glycocalyx is emerging.

\section{Acknowledgments}

Studies reported herein were supported in part by the grants from Westchester Community Trust.

\section{References}

1. Reitsma S, Slaaf DW, Vink H, van Zandvoort MA, oude Egbrink MG. The endothelial glycocalyx: composition, functions, and visualization. Pflugers Arch 2007; 454: 345-59. 
2. Curry FE, Adamson RH. Endothelial glycocalyx: permeability barrier and mechanosensor. Ann Biomed Eng 2012; 40: 828-39.

3. Vink H, Constantinescu AA, Spaan JA. Oxidized lipoproteins degrade the endothelial surface layer : implications for platelet-endothelial cell adhesion. Circulation 2000; 101: 1500-2.

4. Lipowsky HH. The endothelial glycocalyx as a barrier to leukocyte adhesion and its mediation by extracellular proteases. Ann Biomed Eng 2012; 40: 840-8.

5. Pahakis MY, Kosky JR, Dull RO, Tarbell JM. The role of endothelial glycocalyx components in mechanotransduction of fluid shear stress. Biochem Biophys Res Commun 2007; 355: 228-33.

6. Becker BF, Chappell D, Jacob M. Endothelial glycocalyx and coronary vascular permeability: the fringe benefit. Basic Res Cardiol 2010; 105: 687-701.

7. Starling EH. On the absorption of fluids from the connective tissue spaces. J Physiol 1896; 19: 312-26.

8. Adamson RH, Lenz JF, Zhang X, Adamson GN, Weinbaum S, Curry FE. Oncotic pressures opposing filtration across non-fenestrated rat microvessels. J Physiol 2004; 557: 889-907.

9. Levick JR. Revision of the Starling principle: new views of tissue fluid balance. J Physiol 2004; 557: 704.

10. Pappenheimer JR, Soto-rivera A. Effective osmotic pressure of the plasma proteins and other quantities associated with the capillary circulation in the hindlimbs of cats and dogs. Am J Physiol 1948; 152: 471-91.

11. Levick JR. Capillary filtration-absorption balance reconsidered in light of dynamic extravascular factors. Exp Physiol 1991; 76: 825-57.

12. Levick JR, Michel CC. Microvascular fluid exchange and the revised Starling principle. Cardiovasc Res 2010; 87: 198-210.

13. Curry FR. Microvascular solute and water transport. Microcirculation 2005; 12: 17-31.

14. Adamson RH. Permeability of frog mesenteric capillaries after partial pronase digestion of the endothelial glycocalyx. J Physiol 1990; 428: $1-13$.

15. Huxley VH, Williams DA. Role of a glycocalyx on coronary arteriole permeability to proteins: evidence from enzyme treatments. Am J Physiol Heart Circ Physiol 2000; 278: H1177-85.

16. Jeansson M, Haraldsson B. Morphological and functional evidence for an important role of the endothelial cell glycocalyx in the glomerular barrier. Am J Physiol Renal Physiol 2006; 290: F111-6.

17. van Haaren PM, VanBavel E, Vink H, Spaan JA. Charge modification of the endothelial surface layer modulates the permeability barrier of isolated rat mesenteric small arteries. Am J Physiol Heart Circ Physiol 2005; 289: H2503-7.

18. Ueda A, Shimomura M, Ikeda M, Yamaguchi R, Tanishita K. Effect of glycocalyx on shear-dependent albumin uptake in endothelial cells. Am J Physiol Heart Circ Physiol 2004; 287: H2287-94.

19. Collins SR, Blank RS, Deatherage LS, Dull RO. Special article: the endothelial glycocalyx: emerging concepts in pulmonary edema and acute lung injury. Anesth Analg 2013; 117: 664-74.

20. Rippe B, Townsley M, Thigpen J, Parker JC, Korthuis RJ, Taylor AE. Effects of vascular pressure on the pulmonary microvasculature in isolated dog lungs. J Appl Physiol Respir Environ Exerc Physiol 1984; 57: 233-9.

21. Ehrhart IC, Hofman WF. Pressure-dependent increase in lung vascular permeability to water but not protein. J Appl Physiol (1985) 1992; 72: 211-8.

22. Ehrhart IC, McCloud LL, Orfanos SE, Catravas JD, Hofman WF. Effect of high blood flow on pulmonary vascular permeability to protein. J Appl Physiol (1985) 1994; 76: 2342-7.

23. Dull RO, Cluff M, Kingston J, Hill D, Chen H, Hoehne S, et al. Lung heparan sulfates modulate K(fc) during increased vascular pressure: evidence for glycocalyx-mediated mechanotransduction. Am J Physiol Lung Cell Mol Physiol 2012; 302: L816-28.

24. Tarbell JM. Shear stress and the endothelial transport barrier. Cardiovasc Res 2010; 87: 320-30.

25. Dull RO, Mecham I, McJames S. Heparan sulfates mediate pressure-induced increase in lung endothelial hydraulic conductivity via nitric oxide/reactive oxygen species. Am J Physiol Lung Cell Mol Physiol 2007; 292: L1452-8.

26. Weinbaum S, Zhang X, Han Y, Vink H, Cowin SC. Mechanotransduction and flow across the endothelial glycocalyx. Proc Natl Acad Sci U S A 2003; 100: 7988-95.

27. Frangos SG, Gahtan V, Sumpio B. Localization of atherosclerosis: role of hemodynamics. Arch Surg 1999; 134: 1142-9.

28. Martinac B. Mechanosensitive ion channels: molecules of mechanotransduction. J Cell Sci 2004; 117: 2449-60.

29. Haidekker MA, L'Heureux N, Frangos JA. Fluid shear stress increases membrane fluidity in endothelial cells: a study with DCVJ fluorescence. Am J Physiol Heart Circ Physiol 2000; 278: H1401-6.

30. Li H, Brodsky S, Basco M, Romanov V, De Angelis DA, Goligorsky MS. Nitric oxide attenuates signal transduction: possible role in dissociating caveolin-1 scaffold. Circ Res 2001; 88: 229-36.

31. Rizzo V, McIntosh DP, Oh P, Schnitzer JE. In situ flow activates endothelial nitric oxide synthase in luminal caveolae of endothelium with rapid caveolin dissociation and calmodulin association. J Biol Chem 1998; 273: 34724-9.

32. Ringer P, Colo G, Fässler R, Grashoff C. Sensing the mechano-chemical properties of the extracellular matrix. Matrix Biol 2017; 64: 6-16.

33. Dragovich MA, Chester D, Fu BM, Wu C, Xu Y, Goligorsky MS, et al. Mechanotransduction of the endothelial glycocalyx mediates nitric oxide production through activation of TRP channels. Am J Physiol Cell Physiol 2016; 311: C846-53.

34. Takahashi M, Ishida T, Traub O, Corson MA, Berk BC. Mechanotransduction in endothelial cells: temporal signaling events in response to shear stress. J Vasc Res 1997; 34: 212-9. 
35. Lee JS, Chang MI, Tseng Y, Wirtz D. Cdc42 mediates nucleus movement and MTOC polarization in Swiss 3T3 fibroblasts under mechanical shear stress. Mol Biol Cell 2005; 16: 871-80.

36. Helmke BP, Rosen AB, Davies PF. Mapping mechanical strain of an endogenous cytoskeletal network in living endothelial cells. Biophys J 2003; 84: 2691-9.

37. Hsieh HJ, Liu CA, Huang B, Tseng AH, Wang DL. Shear-induced endothelial mechanotransduction: the interplay between reactive oxygen species (ROS) and nitric oxide (NO) and the pathophysiological implications. J Biomed Sci 2014; 21: 3.

38. Chen Z, Peng IC, Cui X, Li YS, Chien S, Shyy JY. Shear stress, SIRT1, and vascular homeostasis. Proc Natl Acad Sci U S A 2010; 107: 1026873.

39. Nayak L, Lin Z, Jain MK. "Go with the flow": how Krüppel-like factor 2 regulates the vasoprotective effects of shear stress. Antioxid Redox Signal 2011; 15: 1449-61.

40. Mohan S, Mohan N, Sprague EA. Differential activation of NF-kappa B in human aortic endothelial cells conditioned to specific flow environments. Am J Physiol 1997; 273: C572-8.

41. Nigro P, Abe J, Berk BC. Flow shear stress and atherosclerosis: a matter of site specificity. Antioxid Redox Signal 2011; $15: 1405-14$.

42. Bartosch AM, Mathews R, Tarbell JM. Endothelial glycocalyx-mediated nitric oxide production in response to selective AFM pulling. Biophys J 2017; 113: 101-8.

43. Florian JA, Kosky JR, Ainslie K, Pang Z, Dull RO, Tarbell JM. Heparan sulfate proteoglycan is a mechanosensor on endothelial cells. Circ Res. 2003; 93: e136-42.

44. Ma X, Qiu S, Luo J, Ma Y, Ngai CY, Shen B, et al. Functional role of vanilloid transient receptor potential 4-canonical transient receptor potential 1 complex in flow-induced Ca2+ influx. Arterioscler Thromb Vasc Biol 2010; 30: 851-8.

45. Mendoza SA, Fang J, Gutterman DD, Wilcox DA, Bubolz AH, Li R, et al. TRPV4-mediated endothelial Ca2+ influx and vasodilation in response to shear stress. Am J Physiol Heart Circ Physiol 2010; 298: H466-76.

46. Yu J, Bergaya S, Murata T, Alp IF, Bauer MP, Lin MI, et al. Direct evidence for the role of caveolin-1 and caveolae in mechanotransduction and remodeling of blood vessels. J Clin Invest 2006; 116: 1284-91.

47. Tousoulis D, Kampoli AM, Tentolouris C, Papageorgiou N, Stefanadis C. The role of nitric oxide on endothelial function. Curr Vasc Pharmacol 2012; 10: 4-18.

48. Yang YM, Huang A, Kaley G, Sun D. eNOS uncoupling and endothelial dysfunction in aged vessels. Am J Physiol Heart Circ Physiol 2009; 297: H1829-36.

49. Matsushita K, Morrell CN, Cambien B, Yang SX, Yamakuchi M, Bao C, et al. Nitric oxide regulates exocytosis by S-nitrosylation of N-ethylmaleimide-sensitive factor. Cell 2003; 115: 139-50.

50. Lipphardt M, Song JW, Ratliff BB, Dihazi H, Müller GA, Goligorsky MS. Endothelial dysfunction is a superinducer of syndecan-4: fibrogenic role of its ectodomain. Am J Physiol Heart Circ Physiol 2018; 314: H484-96.

51. Motta MC, Divecha N, Lemieux M, Kamel C, Chen D, Gu W, et al. Mammalian SIRT1 represses forkhead transcription factors. Cell 2004; 116: 551-63.

52. Brunet A, Sweeney LB, Sturgill JF, Chua KF, Greer PL, Lin Y, et al. Stress-dependent regulation of FOXO transcription factors by the SIRT1 deacetylase. Science 2004; 303: 2011-5.

53. Winnik S, Auwerx J, Sinclair DA, Matter CM. Protective effects of sirtuins in cardiovascular diseases: from bench to bedside. Eur Heart J 2015; 36: 3404-12.

54. Wang Y, Herrera AH, Li Y, Belani KK, Walcheck B. Regulation of mature ADAM17 by redox agents for L-selectin shedding. J Immunol 2009; 182: 2449-57.

55. Kawahara R, Lima RN, Domingues RR, Pauletti BA, Meirelles GV, Assis M, et al. Deciphering the role of the ADAM17-dependent secretome in cell signaling. J Proteome Res 2014; 13: 2080-93.

56. Kauppinen A, Suuronen T, Ojala J, Kaarniranta K, Salminen A. Antagonistic crosstalk between NF- $\mathrm{B}$ and SIRT1 in the regulation of inflammation and metabolic disorders. Cell Signal 2013; 25: 1939-48.

57. Gil N, Goldberg R, Neuman T, Garsen M, Zcharia E, Rubinstein AM, et al. Heparanase is essential for the development of diabetic nephropathy in mice. Diabetes 2012; 61: 208-16.

58. Springer TA. Adhesion receptors of the immune system. Nature 1990; 346: 425-34.

59. Henry CB, Duling BR. TNF-alpha increases entry of macromolecules into luminal endothelial cell glycocalyx. Am J Physiol Heart Circ Physiol 2000; 279: H2815-23.

60. Mulivor AW, Lipowsky HH. Inhibition of glycan shedding and leukocyte-endothelial adhesion in postcapillary venules by suppression of matrixmetalloprotease activity with doxycycline. Microcirculation 2009; 16: 657-66.

61. Kharabi Masouleh B, Ten Dam GB, Wild MK, Seelige R, van der Vlag J, Rops AL, et al. Role of the heparan sulfate proteoglycan syndecan-1 (CD138) in delayed-type hypersensitivity. J Immunol 2009; 182: 4985-93.

62. van Golen RF, van Gulik TM, Heger M. Mechanistic overview of reactive species-induced degradation of the endothelial glycocalyx during hepatic ischemia/reperfusion injury. Free Radic Biol Med 2012; 52: 1382-402.

63. Becker BF, Chappell D, Bruegger D, Annecke T, Jacob M. Therapeutic strategies targeting the endothelial glycocalyx: acute deficits, but great potential. Cardiovasc Res 2010; 87: 300-10. 
64. Pejler G, Abrink M, Ringvall M, Wernersson S. Mast cell proteases. Adv Immunol 2007; 95: 167-255.

65. Chappell D, Jacob M, Rehm M, Stoeckelhuber M, Welsch U, Conzen P, et al. Heparinase selectively sheds heparan sulphate from the endothelial glycocalyx. Biol Chem 2008; 389: 79-82.

66. Lipowsky HH. Protease activity and the role of the endothelial glycocalyx in inflammation. Drug Discov Today Dis Models 2011; 8: 57-62.

67. Lipowsky HH, Lescanic A. The effect of doxycycline on shedding of the glycocalyx due to reactive oxygen species. Microvasc Res 2013; 90: $80-5$.

68. Becker BF, Jacob M, Leipert S, Salmon AH, Chappell D. Degradation of the endothelial glycocalyx in clinical settings: searching for the sheddases. Br J Clin Pharmacol 2015; 80: 389-402.

69. Yu WH, Woessner JF Jr. Heparan sulfate proteoglycans as extracellular docking molecules for matrilysin (matrix metalloproteinase 7). J Biol Chem 2000; 275: 4183-91.

70. Endo K, Takino T, Miyamori H, Kinsen H, Yoshizaki T, Furukawa M, et al. Cleavage of syndecan-1 by membrane type matrix metalloproteinase-1 stimulates cell migration. J Biol Chem 2003; 278: 40764-70.

71. Gronski TJ Jr, Martin RL, Kobayashi DK, Walsh BC, Holman MC, Huber M, et al. Hydrolysis of a broad spectrum of extracellular matrix proteins by human macrophage elastase. J Biol Chem 1997; 272: 12189-94.

72. Suenaga N, Mori H, Itoh Y, Seiki M. CD44 binding through the hemopexin-like domain is critical for its shedding by membrane-type 1 matrix metalloproteinase. Oncogene 2005; 24: 859-68.

73. Singh A, Satchell SC, Neal CR, McKenzie EA, Tooke JE, Mathieson PW. Glomerular endothelial glycocalyx constitutes a barrier to protein permeability. J Am Soc Nephrol 2007; 18: 2885-93.

74. Singh A, Ramnath RD, Foster RR, Wylie EC, Fridén V, Dasgupta I, et al. Reactive oxygen species modulate the barrier function of the human glomerular endothelial glycocalyx. PLoS One 2013; 8: e55852.

75. Chappell D, Jacob M, Paul O, Rehm M, Welsch U, Stoeckelhuber M, et al. The glycocalyx of the human umbilical vein endothelial cell: an impressive structure ex vivo but not in culture. Circ Res 2009; 104: 1313-7.

76. Chappell D, Hofmann-Kiefer K, Jacob M, Rehm M, Briegel J, Welsch U, et al. TNF-alpha induced shedding of the endothelial glycocalyx is prevented by hydrocortisone and antithrombin. Basic Res Cardiol 2009; 104: 78-89.

77. Mulivor AW, Lipowsky HH. Inflammation- and ischemia-induced shedding of venular glycocalyx. Am J Physiol Heart Circ Physiol 2004; 286: H1672-80.

78. Colburn P, Kobayashi E, Buonassisi V. Depleted level of heparan sulfate proteoglycan in the extracellular matrix of endothelial cell cultures exposed to endotoxin. J Cell Physiol 1994; 159: 121-30.

79. Zullo JA, Fan J, Azar TT, Yen W, Zeng M, Chen J, et al. Exocytosis of endothelial lysosome-related organelles hair-triggers a patchy loss of glycocalyx at the onset of sepsis. Am J Pathol 2016; 186: 248-58.

80. Kuo MC, Patschan D, Patschan S, Cohen-Gould L, Park HC, Ni J, et al. Ischemia-induced exocytosis of Weibel-Palade bodies mobilizes stem cells. J Am Soc Nephrol 2008; 19: 2321-30.

81. Lowenstein CJ, Morrell CN, Yamakuchi M. Regulation of Weibel-Palade body exocytosis. Trends Cardiovasc Med 2005; 15: 302-8.

82. Rondaij MG, Bierings R, Kragt A, van Mourik JA, Voorberg J. Dynamics and plasticity of Weibel-Palade bodies in endothelial cells. Arterioscler Thromb Vasc Biol 2006; 26: 1002-7.

83. Goligorsky MS, Patschan D, Kuo MC. Weibel-Palade bodies-sentinels of acute stress. Nat Rev Nephrol 2009; 5: 423-6.

84. Rehm M, Bruegger D, Christ F, Conzen P, Thiel M, Jacob M, et al. Shedding of the endothelial glycocalyx in patients undergoing major vascular surgery with global and regional ischemia. Circulation 2007; 116: 1896-906.

85. Svennevig K, Hoel T, Thiara A, Kolset S, Castelheim A, Mollnes T, et al. Syndecan-1 plasma levels during coronary artery bypass surgery with and without cardiopulmonary bypass. Perfusion 2008; 23: 165-71.

86. Nussbaum C, Haberer A, Tiefenthaller A, Januszewska K, Chappell D, Brettner F, et al. Perturbation of the microvascular glycocalyx and perfusion in infants after cardiopulmonary bypass. J Thorac Cardiovasc Surg 2015; 150: 1474-81.

87. Lindberg-Larsen V, Ostrowski SR, Lindberg-Larsen M, Rovsing ML, Johansson PI, Kehlet H. The effect of pre-operative methylprednisolone on early endothelial damage after total knee arthroplasty: a randomised, double-blind, placebo-controlled trial. Anaesthesia 2017; 72: 121724.

88. Arthur A, McCall PJ, Jolly L, Kinsella J, Kirk A, Shelley BG. Biomark Med 2016; 10: 1033-8.

89. Martin L, Koczera P, Zechendorf E, Schuerholz T. The endothelial glycocalyx: new diagnostic and therapeutic approaches in sepsis. Biomed Res Int 2016; 2016: 3758278.

90. Holzmann MS, Winkler MS, Strunden MS, Izbicki JR, Schoen G, Greiwe G, et al. Syndecan-1 as a biomarker for sepsis survival after major abdominal surgery. Biomark Med 2018; 12: 119-27.

91. Donati A, Damiani E, Domizi R, Romano R, Adrario E, Pelaia P, et al. Alteration of the sublingual microvascular glycocalyx in critically ill patients. Microvasc Res 2013; 90: 86-9.

92. Anand D, Ray S, Srivastava LM, Bhargava S. Evolution of serum hyaluronan and syndecan levels in prognosis of sepsis patients. Clin Biochem 2016; 49: 768-76.

93. Johansson PI, Stensballe J, Rasmussen LS, Ostrowski SR. A high admission syndecan-1 level, a marker of endothelial glycocalyx degradation, is associated with inflammation, protein C depletion, fibrinolysis, and increased mortality in trauma patients. Ann Surg 2011; 254: 194-200. 
94. Halbgebauer R, Braun CK, Denk S, Mayer B, Cinelli P, Radermacher P, et al. Hemorrhagic shock drives glycocalyx, barrier and organ dysfunction early after polytrauma. J Crit Care 2018; 44: 229-37.

95. Schmidt EP, Overdier KH, Sun X, Lin L, Liu X, Yang Y, et al. Urinary glycosaminoglycans predict outcomes in septic shock and acute respiratory distress syndrome. Am J Respir Crit Care Med 2016; 194: 439-49.

96. Puskarich MA, Cornelius DC, Tharp J, Nandi U, Jones AE. Plasma syndecan-1 levels identify a cohort of patients with severe sepsis at high risk for intubation after large-volume intravenous fluid resuscitation. J Crit Care 2016; 36: 125-9.

97. Nelson A, Berkestedt I, Schmidtchen A, Ljunggren L, Bodelsson M. Increased levels of glycosaminoglycans during septic shock: relation to mortality and the antibacterial actions of plasma. Shock 2008; 30: 623-7.

98. de Melo Bezerra Cavalcante CT, Castelo Branco KM, Pinto Júnior VC, Meneses GC, de Oliveira Neves FM, de Souza NM, et al. Syndecan-1 improves severe acute kidney injury prediction after pediatric cardiac surgery. J Thorac Cardiovasc Surg 2016; 152: 178-86.

99. Seal JB, Gewertz BL. Vascular dysfunction in ischemia-reperfusion injury. Ann Vasc Surg 2005; 19: 572-84.

100. Carden DL, Granger DN. Pathophysiology of ischaemia-reperfusion injury. J Pathol 2000; 190: 255-66.

101. Warren OJ, Smith AJ, Alexiou C, Rogers PL, Jawad N, Vincent C, et al. The inflammatory response to cardiopulmonary bypass: part 1mechanisms of pathogenesis. J Cardiothorac Vasc Anesth 2009; 23: 223-31.

102. Aydin NB, Gercekoglu H, Aksu B, Ozkul V, Sener T, Kiygil I, et al. Endotoxemia in coronary artery bypass surgery: a comparison of the offpump technique and conventional cardiopulmonary bypass. J Thorac Cardiovasc Surg 2003; 125: 843-8.

103. Riddington DW, Venkatesh B, Boivin CM, Bonser RS, Elliott TS, Marshall T, et al. Intestinal permeability, gastric intramucosal pH, and systemic endotoxemia in patients undergoing cardiopulmonary bypass. JAMA 1996; 275: 1007-12.

104. Oudemans-van Straaten HM, Jansen PG, Hoek FJ, van Deventer SJ, Sturk A, Stoutenbeek CP, et al. Intestinal permeability, circulating endotoxin, and postoperative systemic responses in cardiac surgery patients. J Cardiothorac Vasc Anesth 1996; 10: 187-94.

105. Steppan J, Hofer S, Funke B, Brenner T, Henrich M, Martin E, et al. Sepsis and major abdominal surgery lead to flaking of the endothelial glycocalix. J Surg Res 2011; 165: 136-41.

106. Bruegger D, Jacob M, Rehm M, Loetsch M, Welsch U, Conzen P, et al. Atrial natriuretic peptide induces shedding of endothelial glycocalyx in coronary vascular bed of guinea pig hearts. Am J Physiol Heart Circ Physiol 2005; 289: H1993-9.

107. Jacob M, Saller T, Chappell D, Rehm M, Welsch U, Becker BF. Physiological levels of A-, B- and C-type natriuretic peptide shed the endothelial glycocalyx and enhance vascular permeability. Basic Res Cardiol 2013; 108: 347.

108. Bruegger D, Schwartz L, Chappell D, Jacob M, Rehm M, Vogeser M, et al. Release of atrial natriuretic peptide precedes shedding of the endothelial glycocalyx equally in patients undergoing on- and off-pump coronary artery bypass surgery. Basic Res Cardiol 2011; 106: 111121.

109. Torres Filho I, Torres LN, Sondeen JL, Polykratis IA, Dubick MA. In vivo evaluation of venular glycocalyx during hemorrhagic shock in rats using intravital microscopy. Microvasc Res 2013; 85: 128-33.

110. Kozar RA, Peng Z, Zhang R, Holcomb JB, Pati S, Park P, et al. Plasma restoration of endothelial glycocalyx in a rodent model of hemorrhagic shock. Anesth Analg 2011; 112: 1289-95.

111. Potter DR, Jiang J, Damiano ER. The recovery time course of the endothelial cell glycocalyx in vivo and its implications in vitro. Circ Res 2009; 104: 1318-25.

112. Rehm M, Orth V, Kreimeier U, Thiel M, Haller M, Brechtelsbauer H, et al. Changes in intravascular volume during acute normovolemic hemodilution and intraoperative retransfusion in patients with radical hysterectomy. Anesthesiology 2000; 92: 657-64.

113. Rehm M, Haller M, Orth V, Kreimeier U, Jacob M, Dressel H, et al. Changes in blood volume and hematocrit during acute preoperative volume loading with $5 \%$ albumin or $6 \%$ hetastarch solutions in patients before radical hysterectomy. Anesthesiology 2001; 95: 849-56.

114. Jackson R, Reid JA, Thorburn J. Volume preloading is not essential to prevent spinal-induced hypotension at caesarean section. Br J Anaesth 1995; 75: 262-5.

115. Kinsella SM, Pirlet M, Mills MS, Tuckey JP, Thomas TA. Randomized study of intravenous fluid preload before epidural analgesia during labour. Br J Anaesth 2000; 85: 311-3.

116. Doherty M, Buggy DJ. Intraoperative fluids: how much is too much? Br J Anaesth 2012; 109: 69-79.

117. Bundgaard-Nielsen M, Secher NH, Kehlet H. 'Liberal' vs. 'restrictive' perioperative fluid therapy--a critical assessment of the evidence. Acta Anaesthesiol Scand 2009; 53: 843-51.

118. Jacob M, Rehm M, Loetsch M, Paul JO, Bruegger D, Welsch U, et al. The endothelial glycocalyx prefers albumin for evoking shear stressinduced, nitric oxide-mediated coronary dilatation. J Vasc Res 2007; 44: 435-43.

119. Zeng Y, Adamson RH, Curry FR, Tarbell JM. Sphingosine-1-phosphate protects endothelial glycocalyx by inhibiting syndecan-1 shedding. Am J Physiol Heart Circ Physiol 2014; 306: H363-72.

120. Jacob M, Paul O, Mehringer L, Chappell D, Rehm M, Welsch U, et al. Albumin augmentation improves condition of guinea pig hearts after $4 \mathrm{hr}$ of cold ischemia. Transplantation 2009; 87: 956-65.

121. Nieuwdorp M, van Haeften TW, Gouverneur MC, Mooij HL, van Lieshout MH, Levi M, et al. Loss of endothelial glycocalyx during acute hyperglycemia coincides with endothelial dysfunction and coagulation activation in vivo. Diabetes 2006; 55: 480-6.

122. Chappell D, Jacob M, Hofmann-Kiefer K, Rehm M, Welsch U, Conzen P, et al. Antithrombin reduces shedding of the endothelial glycocalyx following ischaemia/reperfusion. Cardiovasc Res 2009; 83: 388-96. 
123. Nieuwdorp M, Meuwese MC, Mooij HL, van Lieshout MH, Hayden A, Levi M, et al. Tumor necrosis factor-alpha inhibition protects against endotoxin-induced endothelial glycocalyx perturbation. Atherosclerosis 2009; 202: 296-303.

124. Bruegger D, Rehm M, Jacob M, Chappell D, Stoeckelhuber M, Welsch U, et al. Exogenous nitric oxide requires an endothelial glycocalyx to prevent postischemic coronary vascular leak in guinea pig hearts. Crit Care 2008; 12: R73.

125. Chappell D, Jacob M, Hofmann-Kiefer K, Bruegger D, Rehm M, Conzen P, et al. Hydrocortisone preserves the vascular barrier by protecting the endothelial glycocalyx. Anesthesiology 2007; 107: 776-84.

126. Annecke T, Chappell D, Chen C, Jacob M, Welsch U, Sommerhoff CP, et al. Sevoflurane preserves the endothelial glycocalyx against ischaemia-reperfusion injury. Br J Anaesth 2010; 104: 414-21.

127. Chappell D, Heindl B, Jacob M, Annecke T, Chen C, Rehm M, et al. Sevoflurane reduces leukocyte and platelet adhesion after ischemiareperfusion by protecting the endothelial glycocalyx. Anesthesiology 2011; 115: 483-91.

128. Wheeler-Jones CP, Farrar CE, Pitsillides AA. Targeting hyaluronan of the endothelial glycocalyx for therapeutic intervention. Curr Opin Investig Drugs 2010; 11: 997-1006.

129. Song JW, Zullo JA, Liveris D, Dragovich M, Zhang XF, Goligorsky MS. Therapeutic restoration of endothelial glycocalyx in sepsis. J Pharmacol Exp Ther 2017; 361: 115-21.

130. Vlodavsky I, Ilan N, Naggi A, Casu B. Heparanase: structure, biological functions, and inhibition by heparin-derived mimetics of heparan sulfate. Curr Pharm Des 2007; 13: 2057-73.

131. Mannello F, Raffetto JD. Matrix metalloproteinase activity and glycosaminoglycans in chronic venous disease: the linkage among cell biology, pathology and translational research. Am J Transl Res 2011; 3: 149-58.

132. Mannello F, Medda V, Ligi D, Raffetto JD. Glycosaminoglycan sulodexide inhibition of MMP-9 gelatinase secretion and activity: possible pharmacological role against collagen degradation in vascular chronic diseases. Curr Vasc Pharmacol 2013; 11: 354-65.

133. Broekhuizen LN, Lemkes BA, Mooij HL, Meuwese MC, Verberne H, Holleman F, et al. Effect of sulodexide on endothelial glycocalyx and vascular permeability in patients with type 2 diabetes mellitus. Diabetologia 2010; 53: 2646-55.

134. Hoppensteadt DA, Fareed J. Pharmacological profile of sulodexide. Int Angiol 2014; 33: 229-35.

135. Wan JG, Mu JS, Zhu HS, Geng JG. N-desulfated non-anticoagulant heparin inhibits leukocyte adhesion and transmigration in vitro and attenuates acute peritonitis and ischemia and reperfusion injury in vivo. Inflamm Res 2002; 51: 435-43.

136. Han J, Ding R, Zhao D, Zhang Z, Ma X. Unfractionated heparin attenuates lung vascular leak in a mouse model of sepsis: role of RhoA/Rho kinase pathway. Thromb Res 2013; 132: e42-7.

137. Wildhagen KC, García de Frutos P, Reutelingsperger CP, Schrijver R, Aresté C, Ortega-Gómez A, et al. Nonanticoagulant heparin prevents histone-mediated cytotoxicity in vitro and improves survival in sepsis. Blood 2014; 123: 1098-101.

138. Zhang X, Sun D, Song JW, Zullo J, Lipphardt M, Coneh-Gould L, et al. Endothelial cell dysfunction and glycocalyx - A vicious circle. Matrix Biol 2018 [Epub ahead of print]. 